\title{
6. Collaborative governance: the community sector and collaborative network governance
}

\section{Paul Smyth}

\section{Introduction}

This chapter presents a view of the potential role of the community sector in the emerging forms of social governance within Australia's social-policy regime. This regime is currently in a state of transition and contest and the view here is based on an understanding that before looking at the nuts and bolts of collaboration it is essential to ask the question 'collaboration for what?'. As writers such as Newman (2004) indicate, it is not at all clear what direction the mooted transition from hierarchical and market to network forms of governance will take in different countries (see Considine 2001). Hess and Adams (2002) are persuasive that future organisational forms should not be thought of in terms of more of what we have now; while McDonald and Marston (2005) show how the apparently day-to-day business of governing is shot through with contested understandings of what should be the appropriate 'ends and means' of welfare.

Inevitably, any regime of collaboration will be conditioned by what Salamon and Anheier (1998) have referred to as the 'social origins' of the sector, or what might also be thought of as its 'path dependency'; while others (Evers and Laville 2004) emphasise the importance of understanding the role of the third sector in relation to the configuration of the first and second sectors - namely, the State and the market. Australian history has in fact seen the roles of community organisations, government and business shaped and reshaped several times, which is why it is important to consider the changing configuration of what we call here the three pillars of social governance.

\section{The three pillars of social governance}

The first pillar, the community welfare sector, was assigned a key role in Australian social policy until World War II. A 'welfare society' sustained by wage-earners' welfare was preferred to the welfare state. This model placed great value on what today we would call the voluntary principle, with individuals and community groups trusted to manage their own affairs rather than be managed by government. The 'Australian way' has clearly privileged the contribution of voluntary organisations and is likely to continue to do so. 
The second pillar was founded on the hard-won wisdom of the Great Depression - that often what voluntary groups could do by the 'tens' needed to be done by the 'hundreds' by governments. To guarantee the 'fair go' of Australian social policy, voluntary effort had to be underpinned by government guarantees to all citizens.

These two pillars were synthesised in the 1970s and 1980s in the Keynesian-style welfare state. The government oversaw the macro-social development of its citizens and the community sector provided a complementary role: filling gaps, innovating, being an ombudsman and bringing effective local knowledge into policy development. An older sectarian competitiveness in the sector gave way to collaboration between agencies and with government (Smyth and Wearing 2002). Many of the community-development practices generated in this period still have relevance today. The central aim of including all citizens more directly in the decisions that affected their lives was nicely described in terms of welfare by R. G. Brown's (1975) phrase of developing a 'constituency of the poor'. What was missing in this model was any connection between social and economic development.

The role of the sector changed radically with the switch to free-market economics in the 1990s. The broad aim of social development based on citizenship entitlement was replaced by 'conditional welfare for the few'. In a climate of fiscal austerity, governments turned to contracting out public services via the mechanism of quasi-markets with the aim of achieving greater 'value for money'. Collaboration in the sector was replaced by competition and, for many welfare agencies, growing 'market share' became the central organisational driver. Peak bodies were destabilised and the old ombudsman or advocacy role was compromised. In the literature, this became known as the era of the industry model' and it is this model that is slowly being abandoned as governments and the community sector reach for more joined up collaborative models.

The failings of the industry model - epitomised in the Job Network - have been canvassed in the literature (McDonald and Marston 2005; Mwaiteleke 2007). It is said to be unsuited to the people and places with multiple disadvantage, which are increasingly becoming the core clientele of the Job Network. It is said to be overly centralised with excessive regulation, which hinders responsive professional practice. It is also said to overlook unique local circumstances and directs activity away from collaboration, advocacy, lobbying and networking.

The central failing was the problem identified in the literature as isomorphism - that is, the dynamics of competitive contracting tended to turn the sector into an image of government departments. The sector's 'first-pillar' role with its 'voluntary' character and community-based features was compromised as agencies took on the characteristics of semi-state agencies. The community sector found itself constrained by excessive centralisation and 
regulation and less and less able to respond to human and local complexity. Its ability to exercise local discretion became shackled and capacities for collaboration, advocacy and lobbying seriously impaired.

It is notable that the arguments for an 'industry' model for the community sector are primarily economic and this highlights the importance of the 'third pillar' in social governance - namely, the role of the market. In the welfare-state model, the community sector's role was constructed as social-that is, based on advancing social or human rights. This function was thought to have nothing to do with the economy or indeed was seen as being inherently against the capitalist economy. In the industry-model phase, the goal of economic efficiency often appeared to be opposed to the social-development goals of earlier times.

Today, we see a reconfiguring of this third pillar - the market economy - and in ways that indicate a new convergence of economic and social goals. This is witnessed in part by the continuing expansion of the social responsibility of corporations, but also by the recognition by governments that the primary aim of economic policy today is to create a 'third wave' of productivity growth that will simply not happen without the effective engagement of certain people and places currently excluded from mainstream economic and social participation (Productivity Commission 2007).

For the three sectors to enter a new era of collaborative governance, due attention needs to be paid to this emerging policy framework. It is no longer useful to think of social policies in terms of 'ending welfare dependency' or 'ending welfare as we know it' with the sub-goal of ensuring conditional welfare only for the few. Not only will there be a participation and productivity penalty for allowing continuing social exclusion, there will be a growing economic cost in terms of services needed to address the fallout of social neglect.

\section{The third sector: social investment, capabilities and a new service model}

In this time of transition it is paramount that we ask afresh just what is distinctive about the contributions the three sectors should make to the new forms of collaborative governance. The third sector's contribution was not well conceived in terms of the industry model, in which differences between the sectors became blurred as each was cast as a competitive player in what were styled 'quasi-markets'. In the new, networked collaborative model of governance that we see as desirable, a premium needs to be placed on what is distinctive about the roles and products that each agency brings to the ensemble.

While the focus here is on the third sector, this needs to be considered alongside the other two sectors. While it cannot be developed here, there appear to be significant shifts in thinking about the roles of government, for example, from the 'new public management' to the 'strategic-governance' model as discussed 
by Gallop (2006), and of the economy, from the pure market exchange model of the 1990s to a more Schumpeterian political economy, which highlights the importance of evolving key institutional networks that foster innovation, knowledge transfer, research and development.

As already mentioned, this understanding of the economy has been overlaid increasingly by a sense of the importance of its social foundations. The human-capital agenda of the Council of Australian Governments (COAG), for example, has been increasingly linked to the wellbeing agenda. Therefore investments in the early years, for example, or in the 'long tail' of under-performing Australian youth are seen to be as much economic as social in value.

Of course, simply acknowledging the need for a greater role for social policy does not tell us a lot about how to reconfigure the governance roles of the three sectors. Clearly, there are no hard and fast rules, but as noted above it is likely in view of our history that in Australia there will continue to be a mixed economy of welfare based on the public and for-profit sectors with governments seeking to sustain an underlying commitment to a 'fair go' for all citizens. More specifically, however, we need to revisit the role of the third sector and review what has been its historically proven, different and indispensable role in engaging with those least able to access either government or private services.

The literature expresses this role in terms of addressing market and government failures (Bowles and Gintis 2002). It suggests that the community sector, because of its local reputation, respect and connectedness, is likely to be the initiator of community-based economic activity and to understand local community dynamics, needs and possibilities. It is also likely to be able to generate the trust and cooperation that local initiatives require to succeed (Teague 2007; Halpern 2004; Arrow 1999).

Often this capacity to engage is linked to an ability to generate 'social capital'. While this is possibly valuable, it remains a vacuous way of capturing what the third sector along with its network partners is likely to be aiming to achieve. Here it is arguably more useful to think in terms of the specific social and economic objectives around which the sectoral collaboration is organised. Following the United Kingdom and the European Union, for example, it would appear to make more sense to have a set of explicit objectives for growth, employment, social inclusion and sustainability by which to benchmark and measure the efforts of the networks.

It is arguable that Sen's notion of 'capability' provides, rather than social capital, a more robust way of thinking about the economic and social purposes of public investment. It cannot be developed here (see Bonvin and Farvaque 2006), but the Sen framework also suggests the kind of capacities that will be needed in the third sector if it is to make its distinctive contribution to the new collaborative 
models. Under the industry model, third-sector agencies have tended to become suppliers of centrally packaged services to passive consumers. This is what is funded and there is little spare for developing different services for people not well served by what has become a 'one-size-fits-all' approach. A capabilities model suggests that effective services will flourish when there are engaged communities and that new funding arrangements ought to have a premium paid for community-building work as an end in itself.

With the Sen approach, the focus shifts to the sets of entitlements people ought to have if they are to be able to choose the life they value - or to convert 'capabilities' into 'functionings'. This imposes obligations on governments to ensure opportunities are real. In terms of service delivery, it suggests a model in which service users have an effective voice with real freedom to negotiate their pathway in a fair and reasonable way. The model also advances that central authorities are important for resourcing and accountability and that local, reflexive regulation is needed for local actors to have autonomy, with the institutional environment able to listen.

These principles would allow the development of a new kind of local network of government, business and third-sector agencies, which could create an institutional environment with the capacity to tap into local aspirations and exercise the autonomy necessary for effective responses.

\section{Conclusion: the whole is more than the sum of its parts}

This chapter has emphasised the importance of locating discussions about how to collaborate within a wider consideration of the ends and means of social policy and with particular reference to the national context. It has been proposed that the postwar period has seen a shift from a welfare-state collaborative model to a contract state-industry model and that the evolution of collaborative or network governance signals that we are in the midst of a third major transition.

Within these shifts we have identified the changing goals of social administration. The welfare state was identified with promoting citizenship-based social development. The market model rejected positive state intervention for social purposes and sought to restrict welfare to the deserving few. Now a new set of goals is forming around social investment in an inclusive society in which all people have the opportunities to realise their capabilities.

Achieving these goals, especially those for engaging the excluded, presents new challenges for social governance. Whereas the industry model blurred the differences between the sectors, collaborative governance requires a heightened sense of what makes the sectors distinctive and of what is required to maximise their unique contributions.

In this regard, the negative views about the role of governments characteristic of the 1990s need to give way to a view of government as the strategic agency 
responsible for overall outcomes but working through relevant networks. Governments need to develop this role in ways that include facilitating information sharing, research, development and innovation within relevant networks. Government has a key role to play in bringing the sectors together and enabling them to achieve shared, inter-sectoral policy and program goals.

We have seen that the community sector has historically played an elevated role in the nation's social governance and will undoubtedly play an indispensable role in terms of maximising workforce participation and productivity improvements as much as social cohesion and inclusiveness. From the third sector's perspective, a key issue will be whether it will be resourced in a way that enables it to achieve these functions. In this regard, it will be important that those responsible for collaboration as a whole ensure that the third sector has the resources and the political independence it requires to make an effective contribution.

\section{References}

Arrow, K. 1999, 'Observations on social capital', in P. Dasgupta and I. Serageldin (eds), Social Capital: A multifaceted perspective, World Bank, Washington, DC.

Bonvin, J. and Farvaque, N. 2006, 'Promoting capability for work: the role of local actors', in S. Deneulin et al. (eds), Transforming Unjust Structures: The capability approach, Springer, Amsterdam, pp. 121-42.

Bowles, B. and Gintis, H. 2002, 'Social capital and community governance', Economic Journal, vol. 112, no. 4, pp. 419-36.

Brown, R. G. 1975, The Management of Welfare: A study of the British Social Service Administration.

Considine, M. 2001, Enterprising States: The public management of welfare-to-work, Cambridge University Press, Melbourne.

Evers, A. and Laville, J. (eds) 2004, The Third Sector in Europe, Edward Elgar, Cheltenham.

Gallop, G. 2006, Strategic planning: is it the new model?, Address to the Institute of Public Administration, New South Wales, November.

Halpern, D. 2004, Social Capital, Polity Press, Cambridge.

Hess, M. and Adams, D. 2002, 'Knowing and skilling in contemporary public administration', Australian Journal of Public Administration, vol. 61, no. 4, pp. 68-79.

McDonald, C. and Marston, G. 2005, 'Workfare as welfare: governing unemployment in the advanced welfare state', Critical Social Policy, vol. 25 , no. 3, pp. 374-401. 
Mwaiteleke, P. 2007, The influence of national competition policy in reshaping human service delivery, PhD thesis, Murdoch University.

Newman, J. 2004, 'Modernizing the state: a new style of governance?', in J. Lewis and R. Surender (eds), Welfare State Change: Towards a third way?, Oxford University Press, Oxford, pp. 69-88.

Productivity Commission 2007, Potential Benefits of the National Reform Agenda, Report to the Council of Australian Governments, Canberra.

Salamon, L. and Anheier, H. 1998, 'Social origins of civil society: explaining the nonprofit sector cross-nationally', Voluntas, vol. 9, no. 3, pp. 213-48.

Smyth, P. and Wearing, M. 2002, 'After the welfare state? Welfare governance and the communitarian revival', in S. Bell (ed.), Economic Governance and Institutional Dynamics, Oxford University Press, Melbourne, pp. 226-43.

Teague, P. 2007, 'Developing the social economy in Ireland?', International Journal of Urban and Regional Research, vol. 31, no. 1, pp. 91-108. 